\title{
A fenomenologia de Martin Heidegger e a especificidade metodológica das Ciências Humanas
}

\author{
Rafael Ribeiro Almeida ${ }^{1}$ \\ Rafaela Magalhães de Paula ${ }^{2}$ \\ Recebido em março de 2020 \\ Aceito em junho de 2020
}

\begin{abstract}
RESUMO
As Ciências Humanas movimentam-se num impasse investigativo desde seu processo de constituição, no século XIX. E isso porque o mesmo modelo metodológico utilizado para investigar objetos especificamente regidos por leis naturais, transpassou-se como referencial para as Humanidades. Em vista disso, a racionalidade ligada às Ciências do espírito se percebe na premência de ir em busca de uma base metodológica própria. Neste sentido, nosso objetivo reside em explicitar a Fenomenologia de Martin Heidegger e sua possível contribuição para o universo temático das Ciências Humanas, em termos de método específico. Para tanto, investiga-se o pensamento de Heidegger em sua primeira fase filosófica representado, em especial, por "Ser e tempo" e "Os problemas fundamentais da fenomenologia", ambos de 1927. A primeira evidência da contribuição heideggeriana no tocante a uma metodologia específica das Humanidades reside no fato de o autor ter introduzido um universo existencial no método por ele elaborado. O segundo indicativo da contribuição heideggeriana basicamente resume-se ao modo como o autor entende o conceito de "compreensão". Assim sendo, indica-se viável propor uma postura metodológica alternativa, que, tal qual as Ciências Naturais, também pretende produzir uma racionalidade: a racionalidade das Ciências Humanas.
\end{abstract}

Palavras-chave: Ciências Humanas; Heidegger; Método fenomenológico; Compreensão.

\section{Martin Heidegger's phenomenology and the methodological specificity of the Humanities}

\begin{abstract}
The Human Sciences have been experiencing difficulties since the initial founding process in the 19th century. And this is because the same methodological model used to investigate natural facts, has also become a standard method for the Humanities. Therefore, the rationality related to the Humanities is perceived in the need to seek its own methodological basis. Therefore, the main objective of our article is to explain Martin Heidegger's Phenomenology and its possible contribution to the context of Human Sciences, from the point of view of the method. Thus, Heidegger's thought in its first philosophical phase is investigated, in particular: Ser e tempo (Being and Time) and Os problemas fundamentais da fenomenologia (The fundamental problems of phenomenology), books published in 1927. The first demonstration of Heidegger's contribution in relation to a specific methodology of the Humanities lies in the fact that the author introduced an existential context in the method he worked on. The second demonstration of Heidegger's contribution basically comes down to how the author understands the

\footnotetext{
${ }^{1}$ Graduando em Filosofia pela Universidade Estadual de Santa Cruz (UESC) - BA, Ilhéus. Áreas de Interesse: Ontologia Fundamental, Filosofia Alemã Contemporânea, História da Metafísica, Fenomenologia Hermenêutica e Filosofia da Existência. E-mail: estudosrafael@gmail.com.

${ }^{2}$ Estudante de graduação em Ciências Sociais na Universidade Estadual de Santa Cruz, Ilhéus, BA.
} 
concept of "understanding". Therefore, it is possible to propose an alternative methodology, which, like the Natural Sciences, also intends to produce a rationality specifically for the Humanities.

Keywords: Humanities; Heidegger; Phenomenology; Understanding.

\section{Considerações iniciais}

Copérnico. Kepler. Galileu. Três de alguns célebres nomes que, em meados do século XVII, nortearam a constituição das ciências tal como as entendemos hoje: objetivas, metódicas, empíricas na comprovação e de linguagem matemática. Como se pode presumir, em vista disso, as primeiras ciências a se constituírem com tais não foram as humanas, as chamadas ciências do espírito, mas, sim: as da natureza. Tais ciências, desde o princípio, lançaram-se no afã de alcançar o conhecimento (dito) verdadeiramente científico de modo a afastar, necessariamente, impressões subjetivas, haja vista que essas ciências, por escopo metodológico, tratam apenas de fatos a mercê de serem estruturados por leis universais - fenômenos astronômicos, físicos, químicos, fisiológicos, por exemplo.

Porém, pergunta-se: e a participação dos sujeitos cognoscentes implicados nesse processo científico? Na verdade, as ciências que se deram ao trabalho de contemplar - mais do que isso, problematizar - a atuação dos sujeitos pensantes na constituição do conhecimento e todo corolário intrínseco a tais sujeitos - a saber: aspectos subjetivos, valorativos, existenciais, conotações ideológicas, a questão da parcialidade etc -, surgiram ulteriormente no século $\mathrm{XIX}^{3}$. De saída, os primeiros esboços de uma teoria geral das Ciências Humanas já apontam, direta ou indiretamente, uma concernência com a referência metodológica sedimentada pelas Ciências da Natureza. Quer dizer, o mesmo modelo metodológico utilizado para investigar objetos especificamente regidos por leis naturais (isto é: leis invariáveis, universais e independentes do comportamento humano), também foi transposta como

\footnotetext{
3 "Assim como as Ciências Naturais se constituíram em um rápido desenvolvimento na primeira metade do século XVII, um período relativamente pouco extenso que abrange Wolf, Humboldt, Niebuhr, Eichhorn, Savigny, Hegel e Scheleiermacher também foi fundamental para as ciências humanas. [...] Sua grande realização metodológica residiu na fundação das ciências humanas sobre factualidades histórico-sociais" (DILTHEY, 2010, p. 38).
} 
padrão para as Humanidades, vide o caso de Augusto Comte: sob a égide das Ciências da Natureza ele se coloca o objetivo de fundar uma nova ciência, a Sociologia - por ele chamada, nesse momento, de física social ${ }^{4}$. Frente a isso, improvável não pensar em certos questionamentos os quais, de modo geral, contemplam o tema do presente trabalho: uma vez que as Ciências Humanas se edificam no interior do mesmo modelo das Ciências Naturais, não estariam as primeiras na iminência de se caracterizaram como desumanizadas, isto é, Ciências Humanas sem o homem? Em sendo assim, o saber produzido pela racionalidade específica da alçada das ciências do espírito, não deve ter a premência de ir em busca de uma base metodológica própria, de modo que fundamente a autonomia das Humanidades? Afinal, o sociólogo não pode se deslocar da sociedade a fim de investigá-la "corretamente", o antropólogo não pode tematizar um “objeto" cultural de maneira a negligenciar os sujeitos existentes, e o mesmo se dá com o historiador em relação à história.

Em sendo assim, urge a necessidade de uma alternativa. Uma alternativa que confira autonomia metodológica às Humanidades em relação aos saberes empíricomatemáticos, sem deixar, com isso, de produzir conhecimento de validade científica. Em vista disso, o objetivo deste trabalho consiste em evidenciar a importância e o alcance decisivo da fenomenologia de Martin Heidegger para o universo temático das chamadas Ciências Humanas [Geisteswissenchaften ${ }^{5}$, de modo a destacar, como

\footnotetext{
4 "a fundação da física social completa o sistema das Ciências Naturais" (COMTE, 1983, p. 30).

${ }^{5}$ A rigor, a tradução literal para o termo alemão Geisteswissenchaften não é "ciências humanas" e sim "ciências do espírito" (por vezes, também se traduz o termo por "ciências da cultura"); dessa maneira utilizaremos tais termos sempre como sinônimos de um mesmo sentido: Geisteswissenchaften. Ademais, cumpre-nos aqui explicitar o que entendemos pelo termo "Ciências Humanas" [Geisteswissenchaften]: de acordo com Wilhelm Dilthey, no texto A construção do mundo histórico nas ciências humanas, a área de Humanidades é aquela cujas ciências compartilham um mesmo objeto de pesquisa, a saber: "a espécie humana" (DILTHEY, 2010, p. 20); não é sem motivo, por exemplo, que tais ciência se valem de conceitos e termos bem como "indivíduos, famílias, associações mais complexas, nações, épocas, movimentos históricos ou séries de desenvolvimento, organizações sociais, sistemas da cultura e outros" (DILTHEY, 2010, p. 21). As ciências humanas, de modo geral, valem-se de tais termos para narrar, descrever, tematizar suas investigações de modo a se referir a um mesmo fato: "à humanidade ou à realidade humano-histórico-social" (DILTHEY, 2010, p. 21). Eis, então, a delimitação do escopo investigativo das ciências humanas mediante as Ciências da Natureza: as primeiras se especificam através de sua relação temática para com a Humanidade. Neste sentido, as Ciências da Natureza não "possuem o seu objeto nas impressões, no modo como essas impressões emergem nas vivências, mas nos objetos que o conhecimento cria, a fim de tornar essas impressões construíveis para si" (DILTHEY, 2010, p. 27). Quer dizer, nas Humanidades o "objeto" sobre o qual elas se debruçam cientificamente é formado a partir de algo como a própria vivência dos homens: "Podemos delimitar agora, por meio de traços característicos bem claros, as ciências humanas em relação às Ciências
} 
desdobramento, a especificidade metodológica dessas Ciências perante às Ciências Naturais [Naturwissenschaft]. Pretendemos indicar, a partir de Heidegger, basicamente na primeira fase de seu pensamento, a possibilidade do conhecimento científico próprio das Humanidades - isto é, as ciências que se debruçam sobre fenômenos históricos, criações literárias, fatos sociais, objetos da cultura e outros - traçar caminhos investigativos diferentes das Ciências da Natureza, e, com isso, não perder sua "positividade" sistemática. Afinal: é possível justificar de direito que existe uma metodologia autônoma das Ciências Humanas? Responder assertivamente esta pergunta configura-se, de alguma forma, como o primeiro passo para se reconhecer a especificidade das Humanidades, e, com isso, atribuir a justa importância da elaboração de um método próprio para o conhecimento sistemático dessas ciências.

\section{Parte I}

Primeiramente, é notável a influência de Martin Heidegger, de modo geral, sobre o pensamento ocidental (e também oriental") contemporâneo: "Heidegger foi o autor cuja obra teve o maior número de análises e interpretações publicadas no mundo, neste século [XX]" (SAFRANSKI, 2000, p. 507); e mais: "É com Ser e tempo que Heidegger deixa de ser uma referência local e ganha o status de um fenômeno único na filosofia do século XX" (CASANOVA, 2009, p. 75). O Filósofo alemão procurou inspirar, deliberadamente e de perto, uma série de autores notadamente do contexto temático das Ciências Humanas, tais como Gadamer, Horkheimer, Oskar Becker, Fritz

\footnotetext{
Naturais. Esses traços residem no citado comportamento do espírito, um comportamento por meio do qual, diferentemente do conhecimento das Ciências Naturais, o objeto das ciências humanas é formado. [...] Na condição de objeto das ciências humanas, ela [humanidade, objeto de tematização das ciências humanas] não surge senão na medida em que estado humanos são vivenciados, em que esses estados ganham expressão em manifestações vitais e essas expressões são compreendidas" (DILTHEY, 2010, p. 28. Grifo nosso).

6 "Nos seus pensamentos, Heidegger procurou paisagens ainda mais distantes. O Oriente, o Japão e, em particular, a China foram os lugares que vistiou dessa forma. Para o Japão o chamavam os seus alunos japoneses, as pinturas de Van Gogh e a poesia de Bashô" (LOPARIC, 2004, p. 33). Ademais: "Tanabe Hajime foi o primeiro filósofo a assinalar, numa resenha destinada aos leitores japoneses e publicada em 1924, o surgimento do fenômeno Heidegger. Conde Kuki, pensador da estética, Keiji Nishitani, um dos pioneiros da filosofia japonesa da religião, Tsujimura Köichi, tradutor e intérprete de Heidegger, e Ueda Yasuharu, leitor heideggeriano e zenbudista do Meister Eckhart, merecem ser destacados" (LOPARIC, 2004, p. 64).
} 
Kaufmann, Herbet Marcuse, Hans Jonas7, H. Arendt ${ }^{8}$, Karl Löwith e vários nomes da Escola de Frankfurt ${ }^{9}$. Além disso, o autor do sentido do Ser teve sua obra posteriormente repercutida - como legado, ou como crítica - no panorama mundial das Humanidades, bem como na França (Albert Camus, Levinas, Sartre, Merlau-Ponty, Foucault, Derrida, Pierre Aubenque, Michel Haar, Jean-Luc Marion, Jean Greisch) ${ }^{10}$, nos EUA $^{11}$, na Croácia ${ }^{12}$, e também na América Latina ${ }^{13}$ de modo geral, por exemplo: Benedito Nunes, Emmanuel Carneiro Leão, Ernildo Stein, Loparic, Jorge Eduardo Rivera, José Gaos, Wagner de Reyna (que precocemente publicou La ontología fundamental de Heidegger em 1939 14); diga-se de passagem "os intérpretes mais numerosos de Heidegger são de língua espanhola” (RESWEBER, 1979, p. 190). Isto posto, evidenciada de uma forma ou de outra a aproximação teórica de Heidegger com relação ao contexto geral das Humanidades, prossegue-se, diante disto, à primeira etapa de nossa pesquisa a qual visa destacar a introdução que o Filósofo alemão realiza de um âmbito existencial no tocante ao seu método fenomenológico e que, "a partir desse momento há uma revolução na história da filosofia e na história das Ciências Humanas" (STEIN, 1988, p. 76. Grifo nosso).

\footnotetext{
7 "A conferência Ontologia, do verão de 1923, deve ter causado uma impressão parecida. Não poucos daqueles que mais tarde teriam fama e posição na filosofia sentaram-se aquela vez aos pés do livredocente Heidegger, que para muitos já era um secreto rei da filosofia, um rei em trajes suevos. Eram Gadamer, Horkheimer, Oskar Becker, Fritz Kaufmann, Herbet Marcuse, Hans Jonas" (SAFRANSKI, 200o, p. 158)

8 "A filosofia política de Hannah Arendt, a hermenêutica filosófica de Hans-Georg Gadamer e o projeto desconstrucionista de Jacques Derrida são apenas alguns exemplos de uma tal influência" (CASANOVA, 2009, p. 9).

9 "Toda a elite intelectual jovem da Alemanha, da França, do Japão e de vários outros países procurou estudar com Heidegger. Os judeus também, entre eles - além de Arendt - Hans Jonas, Karl Löwith, Herbet Marcuse e vários outros membros da futura Escola de Frankfurt" (LOPARIC, 2004, p. 9).

10 "A presença de Heidegger na França é um assunto à parte [...]. Além de trabalhos de Levinas, Sartre, Merlau-Ponty, Foucault e Derrida, os de Pierre Aubenque, Michel Haar, Jean-Luc Marion e Jean Greisch revelam profundas marcas do mestre alemão" (LOPARIC, 2004, p. 63).

"I "Os EUA produziram uma literatura considerável sobre Heidegger, tanto interpretativa quanto crítica, cabendo mencionar obras de Frederick A. Olafson, John Haugeland, Hubert L. Dreyfuss, Richard Rorty e Theodor Kisiel" (LOPARIC, 2004, p. 64).

12 "Na Croácia, o Grupo Práxis de Zagreb tentou pensar Marx a partir de Heidegger, com a conivência de alguns frankfurtianos (Habermas)" (LOPARIC, 2004, p. 64).

${ }^{13}$ Numerosos são os pensadores, tanto na América Latina como na Europa, que superam o plano do simples estudo objetivo e propõem uma reflexão original, criticando ou prolongando o pensamento de Heidegger (RESWEBER, 1979, p. 190).

14 "Alberto Wagner De Reyna (1915): nascido em Lima (Peru), estudou em Berlim com Nicolai Hartmann e Eduard Spranger, e em Friburgo (com Heidegger). [...] Depois de ter sido um dos primeiros a dar a conhecer a filosofia de Heidegger na América hispânica, Wagner de Reyna trabalhou em diversos temas de caráter 'existencial' (a morte, o 'cuidado' etc.)" (MORA, 2000, p. 3054).
} 
A primeira evidência da contribuição heideggeriana no tocante a uma metodologia específica das Ciências Humanas reside no seguinte: Martin Heidegger introduz um universo existencial no método por ele elaborado. É no § 5 de Ser e tempo que o autor explicita (terminológica e filosoficamente) o uso que ele faz do termo "Analítica" [Analytik] cujo propósito consiste em analisar o ser-aí em sua existência de ser-no-mundo. De acordo com Ser e Tempo, dois são os aspectos que internamente se articulam na empreitada da analítica existencial. Por um lado (HEIDEGGER, 1988, p. 39), o existenciário [Existenziell], isto é, a compreensão [Verstehen] que o ser-aí tem da própria existência (dispensando, para isso, qualquer esclarecimento teórico); quer dizer, a acepção heideggeriana de existenciário [Existenziell] diz respeito ao modo como o ente que nós mesmos somos decide existir (decide por suas possibilidades, suas escolhas, etc). Por outro lado (HEIDEGGER, 1988, p. 39), a existencialidade [Existenzialität] refere-se à explicitação filosófica-conceitual no que tange à compreensão que o ser-aí tem de si mesmo, ou seja, a existencialidade é relativa à explicitação temática da estrutura existenciária do Dasein. É em função desse raciocínio que Ser e Tempo não parte de um determinado conceito de (estrutura do) Dasein, antes, porém: "sem uma compreensão existenciária, toda análise da existencialidade permanece sem solidez" (HEIDEGGER, 2005, p. 105). Em suma: o ente preliminarmente dado em seu próprio ser equivale à compreensão existenciária [Existenziell], e o esforço metodológico de alcançar um conceito formal de sua estrutura equivale à análise (interpretação) da existencialidade [Existenzialität]. Isso nos permite assinalar, por conseguinte: todas as explicações que decorrem da analítica existencial do ser-aí provêm de sua existencialidade, daí o porquê de todos os caracteres ontológicos do Dasein são chamados por Heidegger de modalidades existenciais, "porque eles se determinam a partir da existencialidade" (HEIDEGGER, 1988, p. 80). Nesse sentido, Ernildo Stein, eminente intérprete brasileiro de Heidegger, ressalta: "a fenomenologia vem ligada a analítica existencial, ao menos em Ser e tempo" (STEIN, 2011, p. 54). Vejamos, então, o liame estabelecido por Heidegger entre seu método fenomenológico e um contexto existencial.

O método utilizado por Heidegger em sua obra capital é o da fenomenologia que, embora possua raízes na acepção de seu mestre Edmund Hurssel, é reinterpretado 
em Ser e Tempo em íntima articulação com um âmbito ontológico-existencial. Pela fenomenologia, Heidegger permite ver o Dasein enquanto ente que se mostra por si mesmo, uma vez liberado de seus encobrimentos. Através da descritividade fenomenológica, Ser e Tempo traz à luz o fenômeno ontológico-existencial do ser-aí, quer dizer, interpreta-o não de fora para dentro, mas, isto sim, de "dentro" - quer dizer: a partir de sua própria existência - para "fora", visto que Heidegger metodologicamente parte do Dasein, em si mesmo e por si mesmo, e é por ele conduzido em toda sua analítica existencial: "a interpretação ontológica projeta o ente preliminarmente dado em seu próprio ser, de modo a chegar ao conceito de sua estrutura" (HEIDEGGER, 2005, p. 104). À medida que Ser e Tempo, do ponto de vista de seu método fenomenológico, baseia-se no Dasein e nele se assegura enquanto ponto de partida conveniente, o que se visa é compreendê-lo em sua existência, entendendo-a como sua própria possibilidade de ser ou de não ser si mesmo em termos ontológicoexistenciais. É em vista dessa relação entre fenomenologia e analítica existencial que chamamos a atenção para a inserção realizada por Heidegger de um âmbito existencial no tocante ao contexto metodológico, e como isso contribui positivamente para um fazer metodológico específico das Humanidades. O esforço metodológico de Heidegger consiste em partir do plano existencial no qual o ser-aí compreende-se a si mesmo, com o propósito de descrever fenomenalmente sua constituição fundamental de serno-mundo em que repousa o sentido de seu ser, a fim de, em última instância, desanuviar o horizonte para interpretar o sentido do Ser em geral ${ }^{15}$.

Seguindo o raciocínio, na medida que Heidegger, através de sua analítica existencial, analisa o Dasein previamente dado em seu próprio ser, com o intuito de alcançar um conceito filosófico de sua estrutura (o que ele chama de ideia formal de existência), o autor se depara com a "seguinte tese: a substância do homem é a existência [Existenz]" (HEIDEGGER, 2005, p. 107). Primeiramente, cumpre destacar que Heidegger não se vale do termo Existenz numa acepção muito ampla, tendo em vista que se trata de um sentido fundamentalmente ontológico e existenciário. Quer

\footnotetext{
15 "Segundo Heidegger, a analítica da Existência constitui o primeiro estágio e a primeira incitação ao desenvolvimento da pergunta acerca do ser, pergunta que determina a direção de semelhante analítica" (MORA, 2000, p. 121).
} 
dizer, por "existência” o autor não tem em vista seu sentido tradicional' ${ }^{16}$ ("esse computador existe"), ou seja, o significado tradicional que indica Vorhandensein, cuja tradução indica ser efetivamente presente ou ser simplesmente dado (algo que já é, ou que já é dado):

Na medida em que, para a visão ontológica, o modo de ser do Dasein não deve
se desvirtuar num modo, mesmo que totalmente indiferente, de ser
simplesmente dado, fez-se necessária a disciplina ininterrupta do
questionamento existencial (HEIDEGGER, 2005, p. 117).

Martin Heidegger escolhe o termo Existenz "para designar o ser deste ente [Dasein]” (HEIDEGGER, 1988, p. 77), e neste sentido o termo diz: poder-ser. Sob a perspectiva terminológica, "existência” resulta da preposição ek e do verbo sistere, que significa "estar para fora”, movimento que parte de dentro para fora, ek-sistir diz respeito ao estar/projetar-se para exterioridade. Em vista disso, o Filósofo alemão traz à tona o conceito de existência num sentido veementemente transitivo: o ser-aí não é um simplesmente existente [Vorhanden], antes, porém, ele precisa se existir: "Portanto, existir não é um estar-presente mas uma realização, um movimento" (SAFRANSKI, 200o, p. 161); Stegmüller corrobora o mesmo sentido: "Existência não é, pois, um estado definitivo, [...] mas uma possibilidade que ele [ser-aí] só é capaz de realizar num engajamento muito ativo e concentrado de si mesmo" (STEGMÜLLER, 1977, p. 120). Na preleção de 1929/30, denominada Conceitos Fundamentais da Metafísica, Heidegger ressalta: "O ente que chamamos ser-aí é o ente de um gênero originariamente próprio, um ente que irrompe para o ser. Desse ente, dizemos que ele existe, isto é, ex-siste; que ele é na essência de seu ser um movimento para fora de si mesmo, sem, porém, abandonar a si” (HEIDEGGER, 2011, p. 469). Quer dizer, o ser-aí precisa conduzir [Führen] sua existência a qual coincide com o seu próprio modo-de-ser, isso de tal modo que elucidar a essência do Dasein equivale à elucidação simultânea de sua própria existência: “A 'essência' do Dasein está em sua existência” (HEIDEGGER, 1988, p. 77. Grifos do autor). Sob esse aspecto o ser-aí não apenas "é”, mas tem a

\footnotetext{
16 "Vê-se desde o iníco que não se pode tratar da existência no sentido clássico, a saber, o fato de ser, de pertencer ao domínio da realidade por oposição ao das possibilidades puras, como o supomos quando dizemos de um objeto: 'existe'" (DARTIGUES, 1992, p. 99).
} 
compreensão (não temática, não teórica) de que é "aí" [da ist]. O modo de ser da natureza material, uma pedra, por exemplo, “é” mas não existe: "a pedra (o material) é sem-mundo"17 (HEIDEGGER, 2011, p. 230). Ou, dito o mesmo por outras palavras, do ponto de vista ontológico somente Dasein existe, o ente que nós mesmos somos é o único ente existente: “o homem é o único Eksistente, o único questionador entre os outros entes dos quais podemos dizer que são, mas não que existem. É a razão pela qual só o homem vivo e concreto poderá ser chamado Dasein" (DARTIGUES, 1992, p. 130).

Com efeito, as observações precedentes procuraram destacar a concernência entre fenomenologia e analítica existencial segundo o entendimento de Heidegger. Procuramos ressaltar a inserção realizada por Heidegger de um âmbito existencial no tocante ao contexto metodológico, haja vista o esforço do autor de partir do plano existencial no qual o ser-aí ek-siste num sentido transitivo. Dessa maneira, Heidegger situa seu método fenomenológico dentro do universo por excelência humano. Contudo, cabe aqui uma ressalva fundamental. Uma vez articuladas as observações precedentes, significa então - poder-se-ia questionar - que Heidegger confere um caráter existencialista a seu método fenomenológico? Será a fenomenologia heideggeriana o fundo recôndito de uma Filosofia Existencialista? Não obstante, as respostas a essas perguntas devem ser enfaticamente negativas: a relação que Heidegger estabelece entre a fenomenologia e a analítica existenciária reduz-se tãosomente a um mero estágio preparatório para a formulação de uma questão mais fundamental (a questão do sentido do Ser), e não ao contrário (a questão ontológica do Ser subordinada à análise existencial):

O que Heidegger censura a Sartre ou ao menos a razão pela qual ele se mantém à distância disso que se chamou existencialismo, é que tal pensamento volta da questão do ser à do homem como centro de sua preocupação. [...] Não convém, pois, deixar-se iludir pelos temas existenciais

\footnotetext{
${ }^{17}$ Para que se clarifique conceitualmente essa ausência (carência) de mundo, é necessário trazer à liça o que o próprio autor, nessa preleção de 1929/30, entende inicialmente pelo termo "mundo" - o mundo como acessibilidade do ente: "o termo mundo com o significado de acessibilidade do ente" (HEIDEGGER, 2011, p. 256). Nesse sentido, a afirmação “a pedra é sem-mundo” também pode ser expressa, de alguma forma, por "a pedra é sem-acesso", ou seja, à constituição ontológica da pedra pertence uma ausência de acesso, e somente, e tão somente neste sentido, então, que a pedra não tem mundo.
} 
que Heidegger desenvolve notadamente em sua primeira grande obra, $O$ Ser $e$ o tempo, mesmo se esses temas puderam inspirar Sartre na elaboração de sua ontologia. Desde o início, a questão de Heidegger não é outra senão a 'questão do Ser', e, se o ser do homem é nele descrito e analisado, é somente porque no homem se situa o lugar, o 'aí' (Da) onde o Ser se desvela (DARTIGUES, 1992, p. 126).

Ou seja, quando se pretende, no presente trabalho, evidenciar a importância da fenomenologia heideggeriana para o universo temático das Ciências Humanas, de maneira a destacar, na primeira parte do texto, o universo existencial que o autor articula, com isso não se pretende corroborar que Heidegger apresenta uma Filosofia da Existência [Existenzphilosophie] - e, se apresenta, é somente no sentido de uma preparação para a Ontologia Fundamental -, antes, porém, nosso intuito reside em jogar luz sobre a analítica existencial do ser-aí a qual se desentranha, no caso de Heidegger, apenas enquanto via metodológica (no caso dele, para alcançar a pergunta sobre o Ser). Quer dizer, o âmbito existencial é decisivo para as investigações de Heidegger em termos metodológicos, e é em função dessa perspectiva que se pretende evidenciar a positividade dessa contribuição para uma diferenciação metodológica das Humanidades com relação às Ciências da Natureza. A fenomenologia, tal como Heidegger a desenvolve, passa a compreender o sentido da existência do ser-aí: "A 'fenomenologia hermenêutica' deverá, pois, decifrar o sentido do texto da existência, esse sentido que precisamente se dissimula na manifestação do dado" (DARTIGUES, 1992, p. 132). Os existenciários, enquanto fios condutores da analítica da existência, demonstram que Heidegger se vale de um método compreensivo e isso é fundamental para as Humanidades, pois:“ 'compreensão' trabalha com o que transborda das categorias, porque não se trata aí de ontologia da coisa, e sim de um universo existencial humano, ligado à liberdade, às decisões e às ações humanas” (STEIN, 1988, p. 43-44). E mais: "No momento que introduzo o universo existencial ou universo dos existenciais, a partir dos quais ampliam-se as categorias, trazendo-as para dentro do universo humano, desliga-se esta ontologia da coisa" (STEIN, 1988, p. 48). Quer dizer, o autor em questão não traz à liça um método fenomenológico que se propõe alcançar leis universais, necessárias, generalizadas e objetivamente verdadeiras, mas, isto sim: trata-se de um método que se propõe a operar "com o vivo, com o fato que nasce do universo 'vivido'” (STEIN, 1988, p. 45), diferente, portanto, das Ciências Naturais nas 
quais "não há necessidade de levar em conta a capacidade de valoração do indivíduo; os enunciados são neutros, o conhecimento é neutro, no universo das ciências empíricomatemáticas" (STEIN, 1988, p. 46).

Com efeito, as observações precedentes procuraram destacar a tematização existencial articulada por Martin Heidegger; posto isso, passaremos à próxima etapa da nossa investigação a qual versará propriamente sobre o conceito de "compreensão", trazendo à tona, no limite, uma alternativa metodológica própria e específica das assim chamadas Ciências do espírito.

\section{Parte II}

A analítica existencial (sobre a qual tratamos anteriormente) visa extrair as estruturas existenciárias de um determinado ente, qual seja: aquele que nós mesmos somos. Mas, pergunta-se: por que esse e não outro ente? O que move Heidegger a se debruçar, em específico, sobre o modo de ser do ser-aí e não sobre o modo de ser, por exemplo, do ser-vivo ${ }^{18}$ (isto é, o animal com vistas à sua animalidade)? Para se responder a tal questionamento faz-se necessário, primeiramente, explicitar qual o propósito filosófico de Heidegger com essa sua análise ontológico-existencial. Martin Heidegger visa, em última instância, revolver a questão considerada por ele como a mais fundamental da História da Filosofia, que, embora um dia já feita, desde há muito encontra-se petrificada no esquecimento, a saber: que é Ser? O sentido do Ser em geral é a mola propulsora a partir da qual o autor desentranha seu pensamento filosófico. “Todos os esforços da analítica existencial visam a uma única meta, qual seja, encontrar uma possibilidade de se responder à questão do sentido do Ser em geral” (HEIDEGGER, 2005, p. 176). Em vista disso, pode-se com maior precisão responder a indagação acima: o motivo pelo qual Heidegger concentra seu esforço analítico no tocante ao ser-aí está relacionado com o privilégio ontológico desse ente. Diferente de todos os outros, o ente que nós mesmos somos é capaz de colocar a pergunta sobre o

18 “vida significa: ser sob o modo de ser do animal” (HEIDEGGER, 2011, p. 269). 
Ser, e, ao mesmo tempo, ter uma compreensão (ou pré-comprensão ${ }^{19}$ ) preliminar acerca do Ser em geral. Por outras palavras: o modo de ser do ser-aí mostra-se enquanto via metodológica de acesso à questão mais fundamental da Filosofia. E é justamente isso que revela o privilégio desse ente com relação aos demais: não obstante, o ser-aí pode compreender e interrogar tanto o seu próprio ser, como, também, compreender e interrogar o ser dos entes que ele mesmo não é, justamente porque, diferente dos demais entes, o ser-aí possui uma compreensão (não teórica, não conceitual) do que é Ser: “Toda questão, ontologicamente explícita, sobre o ser do Dasein já se acha preparada [de modo não temático] pelo próprio modo de ser do Dasein" (HEIDEGGER, 2005, p. 105). Em vista disso, Heidegger concentra seus esforços nesse ente ontologicamente privilegiado: "O animal não pode filosofar; Deus não precisa filosofar. Um Deus que filosofasse não seria um Deus porque a essência da filosofia é ser uma possibilidade finita de um ente finito" (HEIDEGGER, 2009, p.4. Grifo nosso). Porque à estrutura ontológica do Dasein há a possibilidade de compreender é que ele e capaz de - e nisso reside nosso privilégio ontológico - desvelar tanto o ente em seu ser (o que Heidegger chama de verdade ôntica), como é capaz de desvelar o ser do ente (verdade ontológica ${ }^{20}$ ):

\begin{abstract}
Só conseguimos apreender o ente enquanto tal [verdade ôntica], o ente enquanto ente, se compreendemos algo assim como o ser [verdade ontológica]. Por mais que de início a compreensão se dê de maneira tosca e não conceitual, se não compreendêssemos o que realidade efetiva significa, então o ente efetivamente real permaneceria velado. [...] Se não compreendêssemos o que é existência e existencialidade, então nós mesmos não conseguiríamos existir enquanto seres-aí (HEIDEGGER, 2012, p. 20. Grifos nosso).
\end{abstract}

Posto o debate nesses termos, cabe-nos destacar notadamente um termo em especial a fim de avançarmos com direção ao objetivo de nosso texto: compreensão [Verstehen]. “O homem já sempre compreende o ser. A existência é compreensão de ser. [...] Desse modo abre-se o lugar em que se revela o ser, que já sempre se manifesta na pré-compreensão" (STEIN, 2011, p. 45). A acepção heideggeriana de compreensão é

\footnotetext{
19 "A compreensão do ser, ainda não reduzida ao conceito, designamos, por isso, compreensão préontológica ou também ontológica, em sentido mais amplo" (HEIDEGGER, 1999, p. 299).

20 "verdade ôntica e ontológica sempre se referem, de maneira diferente, ao ente em seu ser e ao ser do ente" (HEIDEGGER, 1999, p. 300. Grifo nosso).
} 
central no que diz respeito à contribuição desse autor para uma metodologia específica das Ciências Humanas:

Dado que o saber humano até esse momento [a passagem se refere ao século $\mathrm{XVIII}$ ], a ciência necessariamente estava ligado à questão das categorias [as dez categorias de Aristóteles], dos predicamentos, ou dos conceitos a priori de Kant [as doze categorias em Kant], e dado que, com o universo da analítica existencial, da Escola Histórica e de toda a tradição hermenêutica, se faz, se cria um universo aberto, o saber que passa a surgir nas ciências da cultura, nas ciências históricas, tem um caráter diferente; mas ele deve ser fundamentado sob o ponto de vista epistemológico, lógico e metodológico, e é para isso que são introduzidos então os termos 'compreender', 'compreensão'. Esses termos não são introduzidos de uma maneira simplesmente aleatória para indicar 'conhecer', 'saber que', ou coisa parecida. São introduzidos justamente porque, assim como o 'explicar' está ligado ao universo categorial e à ontologia da coisa, 'compreender' e 'compreensão' estão ligados ao universo histórico, da cultura, dos existenciais, a partir de Heidegger, através dos 'modos de ser' do 'ser-aí' ou através da ideia das 'formas da vida' que não se deixam esgotar através das 'categorias'. É então que a palavra 'compreender' adquire seu estatuto fundamental (STEIN, 1988, p. 40. Grifos nosso).

Nesse sentido, o segundo indicativo da contribuição heideggeriana no que tange a uma metodologia especificamente própria às Humanidades, por assim dizer, basicamente resume-se ao modo como o autor entende o conceito de compreensão. A compreensão é um dos existenciários explicitados pela analítica existencial de Heidegger, ou seja, é uma estrutura ontológica-originária do ser-aí e não um recurso cognoscitivo a partir do qual o homem "entende" algo. Portanto, tratando-se da acepção heideggeriana de compreensão, exclui-se todo sentido de "compreender" enquanto um órgão do conhecimento, daí o equívoco terminológico de se traduzir o vocábulo alemão Verstehen para a palavra em português "entendimento", conforme incorreu no erro a recente edição bilíngue traduzida por Fausto Castilho ${ }^{21}$, embora frequentemente elogiada pelo "discurso consideravelmente mais fluido, com fraseologia direta e isenta das afetações estilísticas" (MERTENS-KAHLMEYER, 2013, p. 103). Exclui-se também o sentido ordinário que a palavra recebe no senso-comum

\footnotetext{
${ }^{21}$ Castilho optou por traduzir a palavra alemã Verstehen por "entendimento" a fim de aproximar tal vocábulo alemão do latino intellegere. No entanto, o termo Verstehen designado pelo prefixo Ver (pré, antes) e pelo verbo Stehen significa etimologicamente "permanecer antes", e é justamente essa concepção que Heidegger tem em vista com o uso do termo. Traduzir esse termo para o português "entendimento" de alguma forma ofusca esse sentido originário.
} 
("Você me compreendeu?" “Ah, sim, eu te compreendi!”22). Antes, porém, Martin Heidegger aborda a compreensão como um existencial, que, enquanto tal, diz respeito ao próprio modo de ser do ser-aí: "Pertence a esse ente [homem] o compreender ser que possibilita pela primeiríssima vez toda postura comportamental em referência ao ente. A compreensão de ser possui ela mesma o modo de ser do ser-aí humano” (HEIDEGGER, 2012, p. 29). Ou seja, o Dasein é um ente cujo modo de ser consiste em encontrar-se compreendendo, haja vista que essa (pré)compreensão de Ser o ente humano tem de modo essencial. Quanto a isso, Ernildo Stein diz: "Heidegger coloca a compreensão como um existencial: antes de nos darmos conta nós já compreendemos. O mundo já está compreendido, não há como chegar antes dele e compreendê-lo" (STEIN, 1988, p. 31). Nota-se em vista disso que o substantivo, compreensão, e o verbo, compreender, no caso de Heidegger indicam uma familiaridade originária do homem para com o mundo; quer dizer, a compreensão, "por nós caracterizada como existencial básico do Dasein" (HEIDEGGER, 1988, p. 207), indica uma condição pré-reflexia e préteórica desse ente que nós somos, de modo a dispensar, como secundária, qualquer postura de ordem cognitiva-teórica - sendo esta última não "inferior" ou "falsa", mas, sim, derivada da compreensão, fundada a partir da compreensão, portanto, não fundamental da constituição humana. "O compreender em geral não é primariamente um conhecer, [...] mas ele é uma determinação fundamental da própria existência. É assim que precisamos de fato conceber o conceito de compreender" (HEIDEGGER, 2012, p. 401). Por exemplo: antes de o homem descobrir cientificamente a galáxia como um complexo sistema aglomerado de forma gravitacional, cujo espaço intergaláctico é constituído por estrelas, por remanescentes de estrelas, por gás e por poeira, é preciso que antes, bem antes, o homem já tenha des-encoberto (nisso reside sua compreensão) todo um contexto de mundo a partir do qual o supracitado fato científico aparece para ele. Na medida em que o homem entende de forma interpretativa o livro As formas elementares da vida religiosa, de E. Durkheim, pressupõe-se que bem antes, antes mesmo de o ler, ele já tenha compreendido todo um contexto a partir do qual esse livro se localiza, “Quer dizer, há uma espécie de lugar em que sabemos situá-los. Ora,

\footnotetext{
22 "Desde os gregos até hoje a palavra, no sentido comum usual, vulgar, ordinário, permaneceu com o mesmo referencial semântico; algo que está além de um processo indutivo e além de um processo dedutivo e fica referido à subjetividade de quem conhece" (STEIN, 1988, p. 58)
} 
isto é um processo pré-compreensivo" (STEIN, 1988, p. 59). Reitera-se, nesse sentido, que essa região privilegiada no Dasein - qual seja: a compreensão - equivale à primeira base a partir da qual se dá qualquer conhecimento de ordem científica, ou qualquer relação epistemológica de sujeito-objeto, e isso por um motivo incialmente simples: o ser-aí, antes de "sujeito", é ser-no-mundo. O ser-aí possui compreensão pré-ontológica na medida em que ele pode-ser-no-mundo (o discurso que trata do ser-no-mundo não é uma verificação espacial, ôntica - o homem está dentro do mundo -, mas sim um discurso ontológico e por isso o uso dos hífens). Isso significa que à base de toda postura teórica ou científica jaz a compreensão do Dasein enquanto familiaridade originária para com o mundo: "O compreender, em sua função de desvelamento, não está ligado a um ponto eu isolado, mas ao poder-ser-no-mundo faticamente existente" (HEIDEGGER, 2012, p. 404. Grifos nosso). Numa palavra: o ente que nós mesmos somos é essencialmente e fundamentalmente - ainda que não apenas - compreender.

\footnotetext{
Mesmo no comportamento prático-técnico em relação ao ente, na medida em que lidamos em geral com o ente enquanto ente, reside compreensão de ser. Em todo comportamento em relação ao ente, quer se trate especificamente de conhecimento, o que na maioria das vezes se designa como teórico, quer se trate de um comportamento técnico-prático, já se encontra uma compreensão de ser. Pois só sob a luz da compreensão de ser um ente pode vir ao nosso encontro como ente (HEIDEGGER, 2012, p. 40o).
}

Nesse sentido, o conceito de compreensão, a partir de Heidegger, adquire um status fundamental no sentido de descerrar uma nova direção investigativa no que tange às Ciências Humanas: “a teoria da 'compreensão' pretende elaborar bases epistemológicas, lógicas e metodológicas para servir de 'muleta' à média do universo de estudiosos, nos diversos campos das Ciências Humanas" (STEIN, 1988, p. 41). Com esse termo aqui em questão e todo o universo temático-existencial implicado com ele, torna-se viável um caminho metodológico específico das Humanidades, tendo em vista que "não é indispensável às ciências do homem seguirem os caminhos traçados pelas Ciências da Natureza. Elas podem perfeitamente utilizar métodos próprios, diferentes do da física, matemática, sem perder, por isso, sua 'positividade”" (VANCOURT, 1964, p.43). E isso porque o universo temático relacionado com a "compreensão" não se propõe um conhecimento de caráter universal, mas, isto sim, circunscreve-se tão- 
somente ao escopo científico das Humanidades, de modo a não se dispor a analisar os "objetos" da natureza, mas, sim, os fatos sociais, culturais e históricos, e "isso significa que se passa a analisar aquilo que é produzido pelo ser humano" (STEIN, 1988, p. 40). Ademais, o cientista que se lança no afã de uma investigação teórica de maneira a operar com o termo "compreensão", muito possivelmente não colidirá com o problema da valoração, já que, por excelência, não há compreensão sem valoração:

não há formas de vida que não se expressem em valor, ou 'modos de ser' do 'ser-aí', que não estejam sempre ligados a um certo sentido, o que significa, a um certo valor. Não há captação pela compreensão em que não haja o sentido acompanhando o valor (STEIN, 1988, p. 46. Grifo nosso).

Nas Ciências da Natureza, busca-se entender e explicar [Erklären] aquilo que se entende 23 - "Nas Ciências Naturais buscam-se razões explicativas hipotéticas para a individuação" (DILTHEY, 2010, p. 73) -, já no caso das Ciências do espírito o objeto "espiritual" surge no compreender - "Uma ciência só pertence às Ciências Humanas se o seu objeto nos é acessível por meio do comportamento que está fundado na conexão entre vida, expressão e compreensão" (DILTHEY, 2010, p. 29). Quanto a isso, Wilhelm Dilthey - de quem Heidegger inicialmente recupera a discussão acerca do termo "compreender"24, ainda que o Filósofo de Meßkirch atribua outro sentido a tal conceito $^{25}$ - ressalta que:

Essa compreensão designa não apenas um comportamento metodológico
peculiar; o que assumimos em relação a tais objetos entre as Ciências
Humanas e as Ciências Naturais não se trata apenas de uma diferença na
posição do sujeito em relação ao objeto, de um modo de comportamento, de
um método. O procedimento da compreensão está fundamentado
objetivamente no fato de o exterior, que constitui o seu objeto, se diferenciar
inteiramente do objeto das Ciências Naturais (DILTHEY, 2010, p. 71. Grifo
nosso).

${ }^{23}$ Assim pensa Gustav Droysen, Friedrich Schleiermacher e Wilhelm Dilthey.

24 "Dele [de Dilthey] Heidegger aceitou não só a ideia de que o homem é um ser histórico, mas também o método da hermenêutica [sic], isto é, da interpretação imanente do sentido do mundo, sem fazer qualquer apelo à transcendência. $\mathrm{O}$ grande empenho de Dilthey foi compreender o homem através dele mesmo" (STEGMÜLLER, 1977, p. 130-1). E mais: "os dois pensadores de que, a nosso ver, Heidegger mais se aproxima são Dilthey e Kierkegaard" (STEGMÜLLER, 1977, p. 161).

${ }^{25}$ À (pré)compreensão de que trata Heidegger é anterior à compreensão da filosofia da vida de Dilthey; Dilthey se refere à vida, Heidegger, à existência; Dilthey tematiza o homem, Heidegger, o modo de ser do homem. 
Mediante à exposição no tocante ao entendimento de M. Heidegger sobre compreensão, entreabre-se como possível defender, enquanto alternativa metodológica, uma forma própria e específica das assim chamadas Ciências do espírito. Não se trata de tornar estas ciências "mais" científicas, mas de renunciar a referência metodológica das Ciências Naturais a fim de construir uma via própria de construção de conhecimento. Assim sendo, indica-se viável propor uma passagem de uma postura metodológica cuja racionalidade é específica das Ciências Naturais, para uma postura metodológica de caráter existencial, que, tal qual as Ciências da natureza, também pretende produzir uma racionalidade: a racionalidade das Ciências Humanas.

\section{Algumas considerações finais}

Em meados do século XIX, iniciou-se o processo de sedimentação das Ciências Humanas com o objetivo de, grosso modo, problematizar a participação dos sujeitos pensantes no processo de conhecimento científico. Logo em sua inicial fundação, tais ciências tiveram sua abordagem metodológica demarcada pelo padrão das investigações metodológicas das Ciências Naturais. O mesmo modelo metodológico utilizado para investigar objetos especificamente regidos por leis naturais, transpassouse como referencial para as Humanidades. Frente a tal impasse, os cientistas das Humanidades - isto é, os cientistas que se debruçam sobre fenômenos históricos, criações literárias, fatos sociais, objetos da cultura e outros - perceberam-se na necessidade de ir em busca de uma base metodológica própria, sem deixar, com isso, de produzir conhecimento de validade científica. Neste sentido, procurou-se ao longo deste texto trazer à tona a Fenomenologia de Martin Heidegger e sua possível contribuição para o universo temático das chamadas Ciências Humanas.

Martin Heidegger, de modo geral, imprimiu notável influência sobre o pensamento ocidental contemporâneo, e, em particular, sobre o contexto temático das Ciências Humanas (tais como Gadamer, Horkheimer, Becker, Kaufmann, Marcuse, H. Jonas, Arendt, K. Löwith e vários nomes da Escola de Frankfurt). A primeira evidência da contribuição heideggeriana no tocante a uma metodologia específica das Ciências Humanas reside no fato de o autor ter introduzido um universo existencial no método 
por ele elaborado: "a partir desse momento há uma revolução na história da filosofia $e$ na história das Ciências Humanas" (STEIN, 1988, p. 76. Grifo nosso). O esforço metodológico de Heidegger consiste em partir do plano existencial no qual o ser-aí compreende-se a si mesmo, com o propósito de descrever fenomenalmente sua constituição fundamental de ser-no-mundo em que repousa o sentido de seu ser. Quer dizer, o autor em questão traz à liça um método fenomenológico que não se propõe alcançar leis universais (necessárias e generalizadas), e sim: trata-se de um método que se propõe a operar "com o vivo, com o fato que nasce do universo "vivido”" (STEIN, 1988, p. 45), diferente, portanto, das Ciências Naturais.

O segundo indicativo da contribuição heideggeriana basicamente resume-se ao modo como o autor entende o conceito de compreensão: "É então que a palavra 'compreender' adquire seu estatuto fundamental (STEIN, 1988, p. 40. Grifos nosso). A compreensão é um dos existenciários explicitados pela analítica existencial de Heidegger, ou seja: compreensão entendida como um existencial, que, enquanto tal, diz respeito ao próprio modo de ser do ente que nós mesmos somos. Isso significa que à base de toda postura teórica ou científica jaz a compreensão do Dasein enquanto familiaridade originária para com o mundo. Numa palavra: o ente que nós mesmos somos é essencialmente e fundamentalmente - ainda que não apenas - compreender. Neste sentido, o conceito de compreensão, a partir de Heidegger, adquire um status fundamental no sentido de descerrar uma nova direção investigativa no que tange às Ciências Humanas: “a teoria da 'compreensão' pretende elaborar bases epistemológicas, lógicas e metodológicas para servir de 'muleta' à média do universo de estudiosos, nos diversos campos das Ciências Humanas" (STEIN, 1988, p. 41). O cientista das Ciências do espírito que se lança numa investigação de maneira a operar teoricamente com o termo compreensão, circunscreve-se tão-somente ao escopo científico das Humanidades, haja vista que o termo relaciona-se, por excelência, com “objetos" sociais, culturais e históricos, e "isso significa que se passa a analisar aquilo que é produzido pelo ser humano" (STEIN, 1988, p. 40). Sendo assim, não se trata de tornar as Humanidades "mais" científicas que as Ciências Naturais, mas, isto sim, de construir uma via própria (no caso de Heidegger, uma metodologia de caráter existencial) para a construção de conhecimento. 


\section{Agradecimentos}

Dedicamos esse texto aos pesquisadores e às pesquisadoras de Ciências Humanas que perseveram na produção séria de pesquisa acadêmica, não obstante os tempos sombrios que assolam a ciência de nosso País.

\section{Referências}

CASANOVA, Marco Antônio. Compreender Heidegger. Petrópolis, RJ: Vozes, 2009.

COMTE, Augusto. Curso de Filosofia Positiva (Os Pensadores). 2. ed. Trad. José Arthur Giannotti e Miguel Lemos. São Paulo: Abril Cultural, 1983.

CERBONE, David. Fenomenologia. Trad. Caesar Souza. Petrópolis: Vozes, 2012.

DARTIGUES, André. O que é a Fenomenologia? 3. Ed. Trad. Maria José J. G. de Alemida. São Paulo: Editora Moraes, 1992.

DILTHEY, Wilhelm. A construção do mundo histórico nas Ciências Humanas. Trad. Marco Casanova. São Paulo: Editora UNESP, 2010.

HEIDEGGER, Martin. Sobre a Essência do Fundamento (coleção Os Pensadores). Trad. Ernildo Stein. São Paulo: Nova Cultural, 1999.

Introdução à filosofia. Tradução de Marco Antonio Casanova. São Paulo: Editora Martins Fontes, 2009.

Os conceitos fundamentais da Metafísica - mundo, finitude, solidão. 2. Ed. Trad. Marco Antônio Casanova. Rio de Janeiro: Forense Universitária, 2011.

Os problemas fundamentais da fenomenologia. Trad. Marco Antônio

Casanova. Petrópolis, RJ: Vozes, 2012.

Vozes, 1988.

Ser e Tempo - parte I. trad. Márcia de Sá Cavalcanti. 2. ed. Petrópolis:

Ser e Tempo - parte II. Trad. Marcia Sá Cavalcante Schuback. 12. Ed. Petrópolis: Vozes, 2005.

LOPARIC, Zeljko. Heidegger. Rio de Janeiro: Jorge Zahar, 2004. 
MERTENS-KAHLMEYER, Roberto. Resenha: Heidegger, Martin. Ser e tempo. Trad. de Fausto Castilho. Editora da Unicamp; Vozes, 2012. 120op. Revista Húmus, Maranhão, n. 8, p. 103-104, agosto, 2013.

MORA, Ferrater. Dicionário de Filosofia - tomo I a IV. Trad. Maria Gonçalves, Adail Sobral, Marcos Bagno, Nicolás Campanário. São Paulo: Loyola, 2000.

NUNES, Benedito. Heidegger \& Ser e Tempo. 2. Ed. Rio de Janeiro: Jorge Zahar, 2004. RESWEBER, Jean-Paul. O Pensamento de Martin Heidegger. Trad. João Agostinho A. Santos. Coimbra: Livraria Almedina, 1979.

SAFRANSKI, Rüdiger. Heidegger - um mestre da Alemanha entre o bem e o mal. Trad. Lya Luft. São Paulo: Geração Editorial, 2000.

SOKOLOWSKI, Robert. Introdução à Fenomenologia. Trad. Alfredo de Oliveira Moraes. São Paulo: Loyola, 2004.

STEGMÜLLER, Wolfgang. A filosofia contemporânea: introdução crítica. São Paulo: EPU, 1977 .

STEIN, Ernildo. Introdução ao pensamento de Martin Heidegger. Porto Alegre: EdiPUCRS, 2011.

- Mundo Vivido - das vicissitudes e dos usos de um conceito de fenomenologia. Porto Alegre: EDIPUCRS, 2004.

Racionalidade e Existência - uma introdução à filosofia. Porto Alegre, RS:

L\&PM Editores, 1988.

Seis estudos sobre 'Ser e tempo'. 3. Ed. Petrópolis: Vozes, 2005.

VANCOURT, R. A estrutura da filosofia: as origens do homem. São Paulo: Duas Cidades, 1964. 